\title{
EL SUICIDIO ASISTIDO EN ITALIA: ¿UN NUEVO DERECHO?
}

\author{
FERNANDO REY MARTÍNEZ \\ Catedrático de Derecho Constitucional \\ Universidad de Valladolid
}

TRC, núm. 46, 2020, pp. 457-483

ISSN 1139-5583

\section{SUMARIO}

I. La reciente jurisprudencia italiana sobre ayuda al suicidio. II. La Ordinanza n. ${ }^{\circ} 207$ (2018), de 24 de octubre. III. La sentenza n. 242 (2019), de 25 de septiembre. IV. Comentario crítico: la Corte constitucional no ha validado la ayuda al suicidio (eutanasia activa directa), sino que ha ampliado el ámbito de la limitación de esfuerzo terapéutico (eutanasia pasiva), permitiendo una alternativa de suicidio asistido a la sedación terminal (eutanasia activa indirecta) en ciertos casos. V. Conclusión: una jurisprudencia de mayor valor simbólico que práctico.

\section{LA RECIENTE JURISPRUDENCIA ITALIANA SOBRE AYUDA AL SUICIDIO}

El suicidio asistido es la disposición de la propia vida, normalmente en un contexto eutanásico, esto es, de enfermedad terminal y/o graves padecimientos físicos o psicológicos, bajo el auxilio de personal sanitario. En la eutanasia activa directa la cesación de la vida la causa la conducta del tercero (el médico u otra persona) a petición del enfermo en un contexto similar al anterior ${ }^{1}$. En estos dos casos, no estamos hablando ya simplemente de la ayuda médica en el morir, donde podríamos incluir la eutanasia activa indirecta (las medidas paliativas que provoquen un acortamiento de la vida) o la eutanasia pasiva (limitación del esfuerzo

1 Para una discusión más precisa y completa de los conceptos aquí utilizados, permítaseme la remisión al libro Eutanasia y Derechos Fundamentales, CEPC, Madrid, 2008 y la bibliografía que allí se cita. Agradezco de modo particular las valiosas sugerencias que me ha prestado para la realización de este trabajo el profesor R. Romboli, de la Universidad de Pisa. 
terapéutico), que son consideradas generalmente válidas ${ }^{2}$, sino, más estrictamente, de otra cosa, de la ayuda médica a morir.

En los últimos años es posible discernir un estándar internacional comparado común en relación con las decisiones del enfermo sobre el final de su propia vida, que en ocasiones se modifica como consecuencia de una suerte de oleada que irrumpe por encima de las fronteras estatales. Hitos de este estándar son, en primer lugar y de modo principal, el cambio de paradigma en la relación médico/ paciente que ha supuesto el principio de autonomía y, correlativamente, el de consentimiento informado, con la facultad que otorga a sus titulares de decidir sobre los propios tratamientos sanitarios y su rechazo e interrupción, incluso los de soporte vital. La medicina paliativa, aunque suponga un acortamiento de la vida (por ejemplo, en el caso de las sedaciones terminales en caso de síntomas refractarios), ha pasado a considerarse un derecho del paciente, el derecho a no sufrir dolor. Por otro lado, el principio de autonomía se ha ido ampliando a los menores de edad, pero mayores de 16 años, y a todas las personas en el caso de no poder tomar decisiones por sí mismos, a través del llamado testamento vital.

Sin embargo, no hay consenso por el momento sobre el reconocimiento de las formas de ayuda a morir. Más bien, la mayoría de Estados siguen inclinándose por su prohibición penal (incluido el nuestro) y son escasos los que permiten la eutanasia activa directa (Holanda, Bélgica o Luxemburgo) o el suicidio asistido por médico y no la eutanasia (el modelo Oregón ${ }^{3}$ ). Y siempre lo hacen como una excepción del deber estatal de proteger la vida, que incluye la punición de este tipo de conductas. Ahí está también, por ejemplo, el caso de Suiza, que permite la ayuda al suicidio, siempre que no sea por motivos «egoístas» (art. 115 Código penal). Como tendremos oportunidad de comprobar, la excepción suiza se ha convertido en el auténtico banco de pruebas de la jurisprudencia del Tribunal europeo de derechos humanos en esta materia ${ }^{4}$.

2 Personalmente, creo que, respecto del ordenamiento español, se trata de manifestaciones del derecho fundamental a la integridad personal del art. $15 \mathrm{CE}$.

3 La experiencia del Estado de Oregón durante la primera década en que estuvo en vigor el sistema fue de «sólo» 1275 suicidios asistidos por médico, unos 60 al año. Es un sistema que se refiere sólo a enfermos a los que se ha diagnosticado una enfermedad terminal (definida con aquella que genera una esperanza de vida inferior a los seis meses), sólo a mayores de edad, mentalmente competentes y residentes en el Estado (para evitar turismo eutanásico). El 35\% de las personas a las que se administra la medicación letal no se la llega a tomar. Pero han utilizado el procedimiento como «seguro emocional» (la libertad de poder hacerlo). En el último año del que disponemos datos, hubo 92 doctores implicados (en España las organizaciones médicas se oponen sistemáticamente a cualquier sistema de eutanasia y esto es un dato crucial a tener en cuenta, sobre todo porque, con las objeciones de conciencia del personal sanitario, cualquier reforma podría llegar a fracasar en la práctica). En la mayoría de los casos de Oregón, las personas tenían cáncer y eran mayores (entre 65 y 84 años). Varios Estados han seguido el «modelo Oregón»: Vermont (2013), Washington (2008), Montana (2015), California (2016), Colorado (2016) y Hawaii (2018). En California, durante el primer año de aplicación de la ley, 2017, se administraron 577 dosis letales, pero sólo se emplearon 374. Por cierto, el 90\%, blancos; parecido número de mujeres y de hombres; el 90,4\%, mayores de 60 años; el 83,4\%.

4 Lo cual no significa que la cuestión sobre la ayuda al suicidio de los enfermos terminales sea completamente pacífica en aquel país. Un ejemplo es la polémica surgida a finales del año 2019 y comienzos de 2020 
En su momento, la Corte Suprema de Canadá (Sentencia Carter v. Canadá, de 2015) ha ofrecido interesantes pautas para una revisión profunda del estándar común sobre suicidio asistido en contexto eutanásico, reconociendo expresamente por primera vez un derecho a adoptar decisiones sobre el final de la propia vida bajo ciertas condiciones. También, como veremos, el Tribunal europeo de derechos humanos ha identificado en la penumbra del derecho a la vida privada del art. $8 \mathrm{CR}$ un nuevo derecho de autodeterminación corporal respecto de la etapa del final de la vida que, aunque no ha llegado tan lejos como la sentencia Carter, permite augurar un profundo cambio de interpretación a favor de una mayor apertura en el reconocimiento de la validez de la ayuda al suicidio.

Pues bien, en la evolución de este contexto internacional, la Corte Constitucional italiana ha pronunciado recientemente una importante decisión, la Sentencia n. 242 (2019), de 25 de septiembre, que ya había adelantado en gran medida, pero, a la vez, suspendido durante once meses para que el legislador pudiera disciplinar la materia, a través de la Ordinanza n. ${ }^{\circ} 207$ (2018), de 24 de octubre, que viene a revisar o a matizar la tradicional disciplina penal italiana de la prohibición absoluta de ayuda al suicidio. La cuestión principal a examinar en este trabajo es, por consiguiente, si el ordenamiento italiano ha pasado a estar entre los Estados que reconocen la validez jurídica del suicidio asistido en contexto eutanásico o no. La tesis que aquí se sostendrá es que no se ha imprimido tal giro, pero que sí se ha creado una zona de penumbra, de grises, entre la conducta prohibida con carácter general de la ayuda al suicidio de los enfermos terminales y la conducta, que era ya válida, de la limitación de esfuerzo terapéutico, difumando los contornos de una distinción clara y precisa de las eutanasias activa directa (dar muerte a otro o ayudar a que se suicide) y pasiva (dejar que la enfermedad siga su curso natural hasta la muerte).

En primer lugar, recordaré los hechos, argumentación y fallo de las dos decisiones de la Corte Constitucional; más tarde, me atreveré a realizar un examen crítico y, por último, concluiré con mi tesis principal, ya sucintamente enunciada.

sobre el acompañamiento espiritual católico a los enfermos que deciden suicidarse con ayuda médica. El documento de la Conferencia episcopal suiza de diciembre de 2019 titulado «Actitud pastoral sobre la práctica del suicidio asistido» muestra una toma de postura tan radical sobre la ayuda al suicidio, que llega a pedir que el agente pastoral «abandone físicamente la habitación del enfermo en el momento del suicidio» (p. 15), que no le asista durante los 16 o 25 minutos de media en que está consciente tras la ingesta del pentobarbital (según sea intravenoso u oral) e incluso que se le llegue a denegar los últimos sacramentos (unción, confesión y eucaristía) (p. 17). Razones alegadas (p. 15): la Iglesia testimonia así a favor de la vida; no da la impresión de que colabora con la ayuda al suicidio; se evita la violencia psicológica de asistir a un acto de este tipo. El suicidio es un acto malo en sí mismo, injustificable en ningún caso (14). Personalmente, aún sin ánimo de terciar en una disputa teológica que me excede, me convence más la posición del arzobispo V. Paglia, presidente de la Academia pontifica para la Vida (en declaraciones efectuadas en enero de 2020): «Acompañar o coger de la mano a alguien que está muriendo es un deber de todo creyente. Nadie puede ser abandonado, incluso si estamos en contra del suicidio asistido». 


\section{LA ORDINANZA N. ${ }^{\circ} 207$ (2018), DE 24 DE OCTUBRE}

La Corte d'assise de Milán planteó a la Corte Constitucional cuestión de legitimidad constitucional del art. 580.1 del Código Penal ${ }^{5}$ (en adelante, CP). El caso del que trae origen la causa se refiere a Fabio Antoniani (en adelante, F.A.), cuyo nombre artístico era D.J. Fabo, quien, tras ser víctima de un grave accidente de tráfico el 13 de junio de 2014, sufría tetraplejia y ceguera, no tenía autonomía ni en la respiración (necesitando la ayuda recurrente de un respirador), ni en la alimentación (era nutrido por vía parenteral) ni en la evacuación; tenía espasmos, contracciones y dolores que no podían ser completamente eliminados por fármacos, salvo mediante una sedación profunda; pero conservaba intactas las facultades intelectivas. Su situación era irreversible. A los dos años del accidente, F.A. decidió pedir, en contra de la voluntad de su madre y de su novia, que se pusiera fin a su vida. Incluso llegó a hacer una huelga de hambre durante unos días. Finalmente, fue acompañado por el acusado Marco Cappato (en adelante, M.C.), del Movimiento Radical italiano y activista pro-eutanasia, a la clínica Dignitas de Pfaffikon, en Suiza, para el suicidio asistido (en Suiza no es punible la ayuda al suicidio), que tuvo lugar el 27 de febrero de 2017. Antes de partir para Suiza, había hecho pública (a través de una filmación y de una apelación al Presidente de la República, Sergio Mattarella, a la sazón) su voluntad de suicidarse con ayuda, afirmando que la viviría «como una liberación». En ese vídeo, F.A. había descrito su propia situación de este modo trágico: «estoy inmerso en una noche sin fin».

A la vuelta del viaje, M.C. se entrega voluntariamente a la policía. Este caso es un buen ejemplo de litigación estratégica. Se le imputó inicialmente por el delito del art. 580.1 CP, más tarde cuestionado ante la Corte Constitucional, tanto por haber reforzado el propósito de suicidio de F.A., como de haberle facilitado su ejecución. El Tribunal que plantea la cuestión considera, no obstante, que la punición de la conducta de ayuda al suicidio del art. $580 \mathrm{CP}$ plantea dudas de compatibilidad con el principio personalista del art. 2 de la Constitución italiana (en adelante CI), aquel que pone a la persona y no al Estado en el centro de la vida social, y con el derecho de inviolabilidad de la libertad personal del art. 13 $\mathrm{CI}$, libertad que «no puede ser concebida en función de una finalidad heterónoma respecto de su propio titular». Además, el derecho a la autodeterminación individual previsto en el art. $32 \mathrm{CI}$ respecto de los tratamientos terapéuticos sanciona la obligación de respetar las decisiones del paciente, incluso aunque de ellas se pueda derivar la muerte. Por otro lado, el Tribunal a quo cuestiona que el art. 580 $\mathrm{CP}$ castigue con la misma pena la ayuda al suicidio que no haya reforzado el propósito del aspirante a suicida, con la misma severa pena (de 5 a 12 años de reclusión) de la conducta de inducción, que es claramente más grave.

5 «Quien determine el suicidio ajeno o refuerce su propósito de suicidio, o bien facilite de cualquier modo la ejecución, será castigado, si el suicidio se produjese, con la reclusión de 5 a 12 años». 
El ponente de la decisión de la Corte Constitucional es F. Modugno. En primer lugar (consideración jurídica — en adelante, $\mathrm{CD}$ - 4), la Corte se desmarca de la tesis del Tribunal a quo sobre la inconstitucionalidad de la tipificación penal de la ayuda al suicidio. Considera, en efecto, que no es contrario a la Constitución el castigo penal de quien concurre en el suicidio de otro, tanto de forma moral, determinando o reforzando su propósito suicida, como de forma material, facilitando «de cualquier modo» su ejecución. No se castiga al suicida, pero se le protege inhibiendo a terceros de cooperar con él. Tampoco se deriva del derecho constitucional a la vida la facultad de disponer de ella con la ayuda del Estado o de un tercero (así se deduce también de la Sentencia del Tribunal Europeo de Derechos Humanos —en adelante, TEDH - Pretty v. Reino Unido, 2002 - CD 5-). Por otro lado, no es posible deducir la inofensividad de la ayuda al suicidio de un genérico derecho de autodeterminación individual, entre otras razones porque su castigo penal protege intereses que merecen tutela por parte del ordenamiento. No ya tanto porque siga vigente la intención del Código penal fascista (1930) que introduce esta norma — por cierto, ya existente en el Código de 1889-, para tutelar la vida humana entendida como bien indisponible en función del interés que la colectividad tiene en la conservación de la vida de los propios ciudadanos, cuanto por una visión contemporánea que mira a la persona como un valor en sí mismo y no como un simple medio para el ejercicio de intereses colectivos (CD 6).

El castigo penal de la instigación y de la ayuda al suicidio, presente en numerosos ordenamientos contemporáneos, protege el derecho a la vida, sobre todo de las personas más débiles y vulnerables, frente a una elección tan extrema e irreparable como es el suicidio y frente a interferencias externas de todo género. Una «evidente razón de ser, sino la mayor» está en relación con la tutela de «las personas enfermas, deprimidas, psicológicamente frágiles, ancianos o en soledad, que pueden ser fácilmente inducidos a poner fin prematuramente a su vida» (CD 6). El legislador penal no puede inhibirse de vetar conductas de ayuda al suicidio en nombre de una concepción abstracta de la autonomía individual que ignore las condiciones concretas de malestar o abandono en las que las decisiones de suicidio se adoptan. Por último en este punto, la jurisprudencia del TEDH reconoce a los Estados un amplio margen de apreciación y señala que la protección de las personas débiles y vulnerables justifica la tipificación penal de la ayuda al suicidio (Pretty v. Reino Unido, 2002).

Así pues, no es inconstitucional sancionar penalmente la ayuda al suicidio. Pero la Corte no se detiene ahí y considera de modo especial o singular situaciones como la que plantea el caso a quo, «inimaginables en la época en la que la norma penal fue introducida», producidas por avances en la tecnología médica capaces de «aplazar la muerte de pacientes graves, pero no de restituirles una suficiencia de funciones vitales» (CD 8). Una situación en la que una persona (a) padece una patología irreversible, (b) fuente de sufrimientos físicos o psicológicos que encuentra absolutamente intolerables, (c) que vive gracias a tratamientos de soporte vital, (d) pero que es capaz de adoptar decisiones conscientes y libres (CD 8). Se trata, en este 
caso, de una «hipótesis en la cual la asistencia a terceros para poner fin a su vida puede presentarse al enfermo como la única vía de salida para sustraerse, dentro del respeto al propio concepto de dignidad personal, a un mantenimiento artificial de la vida, no querido y que él tiene derecho a rehusar según el art. 32, párrafo 2 CI («Nadie puede ser obligado a recibir un determinado tratamiento sanitario si no es por disposición legal»). El caso en examen entra dentro de una hipótesis de este tipo y, por tanto, la decisión de dejarse morir puede ser ya tomada por el enfermo según la legislación vigente art. 32.2 CI y Ley n. ${ }^{\circ} 219$ de 22 de diciembre de 2017 en materia de consentimiento informado y disposiciones anticipadas de tratamiento), por medio de la petición de interrupción del tratamiento de soporte vital y del contextual sometimiento a una sedación profunda continua. La Ley 219 de 2017 (art. 1. 5) reconoce a toda persona con capacidad de obrar el derecho a rehusar o interrumpir cualquier tratamiento sanitario, incluso necesario para la supervivencia, comprendiendo la hidratación y la alimentación artificiales. En este caso, para evitar el sufrimiento del paciente, el médico puede prescribir la sedación paliativa profunda, que concluye en un debilitamiento de las funciones orgánicas del paciente y en su muerte (no necesariamente rápida). El médico debe respetar la voluntad expresa del paciente de rehusar o renunciar al tratamiento (art 1. 6).

En el caso en examen, el interesado solicita ayuda para su suicidio, descartando la solución de la interrupción del soporte vital porque no le aseguraba una muerte rápida. No siendo totalmente dependiente del respirador artificial, la muerte se hubiera producido, si se le hubiese retirado, después de algunos días. Modalidad de muerte que F.A. no consideraba digna y que arrojaba sobre los cuidadores una mayor carga emocional. En este caso, incluso aunque F.A., como enfermo irreversible, pertenece a la categoría de «personas más vulnerables», no entraría en juego, sin embargo, la exigencia de protección que, con carácter general, justifican la represión penal de la ayuda al suicidio. Si la cardinal importancia del valor de la vida no excluye la obligación de respetar la decisión del enfermo de ponerla fin vía interrupción del tratamiento sanitario, no hay razón por la cual el mismo valor deba convertirse en un obstáculo absoluto, con relevancia penal, frente a la petición del enfermo de una ayuda que le sustraiga al desarrollo más lento (apreciado como contrario a la propia idea de muerte digna) de la susodicha interrupción del soporte vital (CD 9). No se ve porqué el mismo sujeto que pueda rechazar el tratamiento de soporte vital deba estar sujeto a una «férrea e indiscriminada protección contra su propia voluntad» cuando se discuta la decisión de concluir su existencia con la ayuda de otros, como «alternativa reputada más digna» a dicha interrupción (CD 9).

De modo que, en este caso, el deber absoluto de ayuda al suicidio termina por limitar la libertad de autodeterminación del enfermo en la elección de las terapias, incluidas las destinadas a eliminar sus sufrimientos, sin que tal limitación proteja otros intereses constitucionales, con la consiguiente lesión del principio de dignidad humana y de igualdad (art. $3 \mathrm{CI}$ ).

Pero esta inconstitucionalidad no puede ser resuelta por la Corte, sino por el legislador penal, quien debe regular quién pueda (sea personal sanitario o no), 
gratuitamente o por precio, ayudar a los pacientes que lo pidan, controlando (a través de diversas posibilidades) ex ante la capacidad de autodeterminación del enfermo, el carácter libre e informado de su elección, la irreversibilidad de la dolencia que padece o la posibilidad de objeción de conciencia del personal médico público, entre otros extremos (CD 10). Una disciplina legal sobre la decisión de algunos pacientes (los que reúnan las cuatro condiciones antes indicadas: patología irreversible, fuente de sufrimientos intolerables, con soporte vital, pero capaces) de liberarse de los propios sufrimientos no sólo a través de una sedación profunda continua y el correlativo rechazo del tratamiento de soporte vital, sino a través del suministro de un fármaco que les provoque rápidamente la muerte, podría ser introducida mediante una mera modificación del art. $580 \mathrm{CP}$, el precepto cuestionado, insertando tal disciplina en el contexto de la Ley 219 de 2017 y su espíritu (CD 10).

Existen diversas posibilidades de regulación penal en este sentido, pero el legislador debe ser cauteloso: la introducción de esta nueva opción no debe provocar la renuncia del sistema sanitario a ofrecer al mismo paciente cuidados paliativos distintos al de la sedación terminal. Los delicados equilibrios de esta regulación no le corresponden a la Corte Constitucional, sino al Parlamento. En consecuencia, la Corte advierte al legislador para que adopte la regulación necesaria para impedir la vulneración constitucional. No habrá decisión hasta la sesión programada del 24 de septiembre de 2019 y durante este periodo permanecerá suspendido también el juicio a quo (CD 11).

La solución adoptada es semejante a la que la Corte Constitucional de Canadá adoptó en Carter v. Canadá (2015): donde declaró inconstitucional una disposición penal análoga a la examinada en la parte en la que prohibía la ayuda médica al suicidio de una persona adulta que había claramente consentido a poner fin a su propia vida y que sufría de una patología grave e incurable que la provocaba sufrimientos persistentes e intolerables. En aquel caso, la Corte canadiense suspendió por 12 meses la eficacia de la decisión para dar una oportunidad al Parlamento para que elaborara una ley sobre la materia.

También es semejante a la sentencia de 25 de junio de 2014 de la Corte Suprema del Reino Unido, Nicklinson y otros. La mayoría de magistrados afirmaron que era «institucionalmente inapropiado» para la Corte declarar la incompatibilidad de la norma enjuiciada con el art. 8 del Convenio europeo de derechos humanos sin dar al Parlamento la oportunidad de considerar el problema. Esta Sentencia subrayó que declarar, incluso parcialmente, la validez de la ayuda médica al suicidio, era un problema difícil, controvertido y éticamente sensible, que requiere un enfoque prudente por parte de los tribunales, añadiendo que una cuestión así reclama una valoración profunda por parte del legislador, quien tiene la posibilidad de actuar (tras un iter procedimental en el que pueden coincidir varios expertos y miembros con intereses contrapuestos), dotando una regulación compleja y completa de la materia, que no sólo es penal (CD 11). La Corte apela, pues, al diálogo entre instituciones y a su leal colaboración. 


\section{LA SENTENZA N. ${ }^{\circ} 242$ (2019), DE 25 DE SEPTIEMBRE}

La invitación dirigida por la Corte Constitucional no fue, a pesar de diversos intentos, contestada por el Parlamento italiano, que no ha logrado aprobar en este periodo regulación alguna. Y, por eso, la declaración de ilegitimidad constitucional, en los términos expuestos por la Ordinanza 207 de 2018, «no parece ulteriormente procrastinable» (ritenuto in fatto, 6), de modo que la Sentencia 242/2019 procede a ello. Concretamente, declara inconstitucional el art. $580 \mathrm{CP}$, pero sólo «en la parte en que no excluye la punibilidad de quien... facilite la ejecución del propósito de suicidio, autónoma y libremente formado, de una persona mantenida con vida con un tratamiento de soporte vital, afectada de una patología irreversible, fuente de sufrimientos físicos o psicológicos que considere intolerables, pero plenamente capaz de adoptar decisiones libres y conscientes, siempre que tales condiciones y la modalidad de ejecución sean verificadas por una estructura pública del servicio sanitario nacional, previo informe del comité ético territorialmente competente».

Se declara inconstitucional el art. $580 \mathrm{CP}$ sólo en el sentido indicado, por no incluir una excepción a la regla general — válida y vigente- de prohibir absolutamente la ayuda al suicidio ajeno. La Corte se cuida mucho, para no vaciar la tutela de las personas más vulnerables, de establecer directamente ciertas cautelas en el diseño de la excepción: (a) se refiere sólo a personas que ya pueden alternativamente dejarse morir mediante tratamientos sanitario de soporte vital; (b) personas capaces, que muestren expresamente su consentimiento al procedimiento de modo claro y unívoco; (c) el médico debe constatar que la enfermedad es irreversible e informar al paciente de todas las posibles alternativas y, por supuesto, ofrecer los cuidados paliativos; (d) se debe prestar, en su caso, apoyo psicológico; (e) el sistema sanitario público debe controlar todas las condiciones de la ayuda al suicidio; (f) la ayuda debe evitar abusos de las personas vulnerables así como cualquier tipo de dolor; $(\mathrm{g})$ deben intervenir los comités de ética sanitaria territorialmente competentes; (h) debe extenderse la objeción de conciencia del personal sanitario a este caso.

Tales cautelas constituyen, sin duda, el núcleo duro, principial, de una futura ley sobre la materia.

\section{COMENTARIO CRÍTICO: LA CORTE CONSTITUCIONAL NO HA VALIDADO LA AYUDA AL SUICIDIO (EUTANASIA ACTIVA DIRECTA), SINO QUE HA AMPLIADO EL ÁMBITO DE LA LIMITACIÓN DE ESFUERZO TERAPÉUTICO (EUTANASIA PASIVA), PERMITIENDO UNA ALTERNATIVA DE SUICIDIO ASISTIDO A LA SEDACIÓN TERMINAL (EUTANASIA ACTIVA INDIRECTA) EN CIERTOS CASOS}

Las decisiones de la Corte Constitucional italiana parecen abrir la posibilidad de la ayuda al suicidio, incluso bajo condiciones estrictas, y, por tanto, de la 
eutanasia activa directa, totalmente prohibida hasta el momento por el ordenamiento italiano, pero, en realidad, lo único que hacen, correctamente, eso sí, a mi juicio, es ampliar el ámbito de la limitación de esfuerzo terapéutico para enfermos terminales, permitiendo el suicidio asistido como una alternativa válida a la sedación terminal. La clave de lectura de las decisiones de la Corte se halla en la exigencia, para poder legitimar la ayuda al suicidio, de que el paciente dependa (permanente o recurrentemente) de dispositivos o tratamientos de soporte vital. Una exigencia, por supuesto, desconocida en los ordenamientos donde sí se permite la ayuda al suicidio en algunos casos. Por eso, como agudamente ha observado C. Cassonato, más que un nuevo derecho, la Corte ha formulado un «buen propósito» ${ }^{6}$, fundamentalmente porque ha añadido ese cuarto requisito que no contemplan el resto de ordenamientos que permiten la ayuda a morir, cual es la necesidad de un soporte vital. En efecto, normalmente se exigen tres cosas para permitir el suicidio o la muerte asistida por personal sanitario: $\left(1{ }^{a}\right)$ un sujeto adulto y capaz para tomar esta decisión, que la adopte de modo totalmente libre; $\left(2 .^{a}\right)$ una enfermedad grave e incurable; y $\left(3 .^{a}\right)$ un sufrimiento físico y/o psicológico intolerable. Pues bien, la Corte italiana, además de estos tres requisitos, requiere uno más que, a mi juicio, transforma por completo la naturaleza de la habilitación, cual es el de vivir ligado a un tratamiento sanitario de soporte. Como sostiene Cassonato, «forzar a un paciente a tener una traqueotomía (para poder respirar) sólo con el propósito de acceder al suicidio asistido parece altamente irrazonable ${ }^{7} »$.

Las decisiones de la Corte en examen presentan, por consiguiente, diversos flancos a la crítica. Desde mi punto de vista, los tres principales son, además del ya expuesto, que es el nuclear, las profundas diferencias en el abordaje de este asunto respecto del ejemplo canadiense, por más que en tales decisiones, la Corte Constitucional italiana se esfuerce en trazar paralelismos entre ellos, y también la forma más bien rápida y superficial con la que se trae la jurisprudencia del Tribunal europeo de derechos humanos. Veámoslo más concretamente.

\section{Análisis comparado de las jurisprudencias italiana y canadiense}

La Sentencia Carter v. Canadá de la Corte Constitucional de Canadá (2015) es relevante porque ofrece, por unanimidad, una argumentación y un fallo que,

6 Assisted suicide in Italy: constitutional right or wishful thinking?, en BioLaw Journal, Rivista di BioDiritto, n. ${ }^{\circ}$ 2, 2019, pp. 147-149.

7 Ibidem, p. 149. Además, en Italia los códigos deontológicos sanitarios, siguiendo la fórmula hipocrática de prohibir hacer daño a nadie, impiden poner fin a la vida de un tercero, de modo que aunque la ayuda al suicidio se reconociera como un nuevo derecho, el personal médico seguiría sin estar autorizado a llevarlo a cabo (p. 149). Evidentemente, esta es también una buena razón para que el legislador discipline con detalle esta materia en el futuro. 
como sugerí en su momento ${ }^{8}$, se ha convertido en un modelo de inspiración de numerosos ordenamientos, como, por ejemplo, el italiano, puesto que es una decisión que se toma expresamente en consideración. La Corte Suprema canadiense consideró que prohibir de modo absoluto la ayuda a morir, en ciertos casos, viola diversos derechos fundamentales. Aún más: de la Sentencia se desprende, en sentido positivo, que la ayuda médica a la muerte es, bajo ciertas condiciones, un auténtico derecho fundamental. De modo que lo que todavía es considerado en casi todos los ordenamientos una conducta penalmente reprochable, pasó a ser valorado en Canadá como un nuevo derecho fundamental.

El caso del que trae origen la causa debuta en 2009, cuando a Gloria Taylor ${ }^{9}$ le diagnostican una esclerosis lateral amiotrófica (ELA), que provoca debilidad muscular progresiva ${ }^{10}$. La señora Taylor no quería «morir lentamente, paso a paso» (p. 11) y planteó una demanda ante el Tribunal Supremo de la Columbia Británica impugnando la constitucionalidad de los artículos del Código Penal que prohíben la ayuda médica a morir. La Señora Taylor se enfrentaba a lo que ella mismo describió como una «cruel elección» entre suicidarse por sí misma mientras pudiera o perder cualquier control sobre el momento y forma de su muerte $^{11}$ (p. 13). Finalmente, la señora Taylor falleció.

En los cuatro primeros párrafos, la Sentencia expone sintéticamente el problema social al que se enfrenta, el conflicto jurídico en que se traduce y el fallo que se alcanza. El problema social: en Canadá es delito asistir a otra persona para poner fin a su vida; por tanto, las personas con una enfermedad grave e irreversible no pueden pedir asistencia médica para morir y «están condenadas a vivir con un sufrimiento serio e intolerable» (párrafo —en adelante, p. 1). Una persona en esta situación tiene dos opciones: suicidarse prematuramente, a menudo por medios violentos o peligrosos; o puede sufrir hasta fallecer por causas naturales. Esta elección «es cruel» (p. 1). El conflicto jurídico: la cuestión en este caso es determinar si la prohibición penal que obliga a las personas a tener que hacer tal elección lesiona su derecho a la vida, libertad y seguridad del art. 7 de la Carta canadiense de Derechos y Libertades (en adelante, CCDL) y/o la igualdad jurídica

8 «La ayuda médica a morir como derecho fundamental. Comentario crítico de la Sentencia de la Corte Suprema de Canadá de 6 de febrero de 2015, asunto Carter v. Canadá». Publicado en Biolaw Journal. Rivista di BioDiritto, n. ${ }^{\circ} 2,2015$, pp. 245-260.

9 El caso se llama Carter v. Canada y no Taylor v. Canada, obviamente, porque la demanda la plantearon la señora Gloria Taylor, pero también otros sujetos, entre ellos Lee Carter y Hollis Johnson, que habían acompañado a la madre de la primera, llamada Kathleen Carter, a una clínica de Suiza para un suicidio asistido por médico. También firmaban el caso un médico partidario de la ayuda médica a morir y la Asociación de Libertades Civiles de la Columbia Británica.

10 Los pacientes con ELA pierden progresivamente la capacidad para usar manos y pies, para caminar, digerir los alimentos e incluso para respirar. En 2010, la condición de la señora Taylor empeoró y tuvo que ir en silla de ruedas. Sufría fuertes dolores. Informó a sus familiares y amigos que deseaba ayuda para morir porque «no quería una muerte horrible».

11 En los párrafos 14 a 18, la Sentencia se hace eco de otros testimonios tanto de suicidios en este contexto, como de muertes terribles de este tipo de enfermos. 
de trato del art. 15. Se trata de un problema que obliga a ponderar valores de gran importancia en conflicto. De un lado, la autonomía y dignidad de un adulto capaz que pide la muerte como respuesta a su condición médica grave e irreversible. De otro lado, la santidad de la vida y la necesidad de proteger al vulnerable de eventuales abusos y errores (p. 2). El Tribunal se inclinará por la primera opción. El fallo: la prohibición penal (art. 241 b) Criminal Code) de la muerte asistida por médico es nula en la medida en que priva a un adulto capaz de dicha asistencia cuando la persona afectada claramente consienta la terminación de su vida y tenga una condición médica (incluyendo enfermedad y discapacidad) que le provoque sufrimientos permanentes intolerables.

La Corte Constitucional falla que la ayuda médica a morir sí limita los derechos a la vida, la libertad y seguridad personales, pero concluye que lo puede hacer, bajo ciertas condiciones, de un modo justificable. La prohibición de asistencia médica a morir limita el derecho a la libertad y seguridad de la señora Taylor porque afecta a la «toma de decisiones médicas que son personales y fundamentales», imponiendo «daño y estrés psicológico» y privándola «del control sobre su integridad corporal ${ }^{12} »$ (p. 65). Según el Tribunal Supremo, la respuesta penal a una condición médica grave e irremediable es «un asunto crítico» respecto de la dignidad y autonomía. El ordenamiento permite a las personas que se hallan en esta situación pedir sedación paliativa, rehusar la nutrición e hidratación artificial, o solicitar la retirada de los equipos de soporte vital, pero, hasta ese momento, les deniega el derecho a pedir ayuda médica para morir. Esto afecta a su capacidad para adoptar decisiones relativas a su integridad corporal y a recibir cuidados médicos y, por tanto, limita su libertad. Dejar que personas como la señora Taylor sigan sufriendo de un modo intolerable y permanente, lesiona su derecho a la seguridad personal (p. 66). La libertad protege «el derecho a adoptar elecciones personales fundamentales de modo ajeno a interferencias estatales»y la seguridad «abarca una noción de autonomía personal» que implica, entre otras cosas, «el control sobre la propia integridad corporal» también sin injerencias de los poderes públicos (p. 64³).

La Corte se niega a reconocer en términos absolutos un derecho constitucional a morir con dignidad, pero, seguramente buscando cierto equilibrio, y de modo más coherente con el fallo que alcanza en este caso, también se niega a aceptar que el derecho a la vida exija una prohibición total de ayuda a morir, esto

12 La Corte considera que la prohibición de ayuda médica a morir «denegaba a los enfermos, seria e irremediablemente, la oportunidad de adoptar una decisión muy importante para su sentido de la dignidad e integridad personales», en el marco de «sus valores vitales permanentes y su experiencia de vida» (p. 65).

13 Es interesante observar que el debate constitucional sobre estas cuestiones varía en cada ordenamiento según se reconozcan concretamente los derechos fundamentales (o no, y cómo) en los respectivos catálogos constitucionales. En este caso, lo que en Canadá llaman derecho a la «seguridad personal» no coincide con lo que en nuestro ordenamiento constitucional se llama «derecho a la libertad y seguridad personal» del art. $17 \mathrm{CE}$, sino, más bien, con el derecho del art. $15 \mathrm{CE}$ a la integridad «física y moral». 
es, que las personas «no puedan ser perdonadas» de su derecho a vivir (p. 63). Esto crearía, según la Sentencia, un «deber de vivir» más que un «derecho a la vida» y negaría la validez del consentimiento para rechazar o retirar los tratamientos de soporte vital.

La Sentencia conecta este nuevo derecho a recibir asistencia médica a morir con el derecho del paciente a tomar las decisiones con autonomía. Se trataría de una facultad más de este derecho a «decidir sobre el propio destino» que habilita a las personas adultas a dirigir el curso de sus cuidados médicos y que subyace al concepto de «consentimiento informado» (p. 67). Es el mismo principio que opera en los casos que afectan al derecho a rehusar el consentimiento a un tratamiento médico o a pedir que el tratamiento sea interrumpido (p. 67). He aquí el punto: la sentencia Carter elimina, dentro del parámetro común comparado en estas materias, la distinción entre eutanasia pasiva y activa indirecta, de un lado, y la eutanasia activa directa de otro. Las hace coincidir dentro del mismo derecho de autonomía del paciente a adoptar decisiones médicas en relación con el final de la vida. La decisión sobre vivir o dejar de hacerlo se enmarca, según la Corte, en el contexto de los valores y experiencia vital de cada persona; ésta debe tener el control de su integridad corporal. Representa la respuesta de cada uno, profundamente personal, al dolor serio y al sufrimiento. Impedir esta decisión lesiona el derecho a la libertad y seguridad personales. Y, por tanto, la Sentencia concluye que el art. 241 b) del Código Penal, en la medida en que prohíbe la asistencia médica a morir a adultos capaces que piden tal ayuda como resultado de una condición médica grave e irremediable que cause un sufrimiento permanente e intolerable, infringe los derechos de libertad y seguridad personales del art. 7 CCDL.

La Corte canadiense argumenta con detalle la proporcionalidad de la ayuda médica a morir. Esto contrasta absolutamente con las decisiones italianas, que hacen de la protección de las personas vulnerables la única razón de la prohibición. Sobre este punto, volveré más adelante.

La Corte observa que el objeto de la prohibición de la muerte asistida por médico es proteger a las personas vulnerables, evitando que fueran inducidas a suicidarse o a que un tercero pusiera fin a su vida en un periodo de especial debili$\mathrm{dad}^{14}$. Este es también el argumento que utiliza la Corte Constitucional italiana. Ahora bien, la Corte canadiense, en un sentido similar a la italiana, sostiene que los límites a los derechos que conlleva la prohibición penal de la ayuda médica a morir no es arbitraria, dado que una prohibición absoluta del suicidio es una medida que puede proteger a los enfermos vulnerables, pero, diferenciándose de las decisiones italianas, afirma que sí es sobre-inclusiva, esto es: no todas las personas que pueden pedir ayuda a morir son vulnerables. El Gobierno canadiense había

14 Lógicamente, la definición del objeto de la Ley es un asunto central. La Corte niega que el objeto de la prohibición penal de la ayuda médica a morir fuera la «preservación de la vida» en general porque tal finalidad sería demasiado amplia e impediría cualquier cambio legal en la materia. 
alegado que «toda persona es potencialmente vulnerable» y que no es fácil determinar a priori quién es vulnerable y quién no, pero la Corte se opone a esta tesis Esta es la diferencia de fondo entre lo decidido por ambas Cortes.

La Sentencia canadiense también cree que la prohibición penal del suicidio es una medida conectada racionalmente a la finalidad de proteger a las personas enfermas vulnerables; se trata de un «método racional de evitarlos» (p. 100). Sin embargo, valorando si la medida es la menos limitativa del derecho, concluye que no. Esta cuestión, como señala el Tribunal, «es el corazón de este caso» y fue el foco principal de la actividad probatoria (p. 103). La prohibición penal absoluta hubiera resultado necesaria si se demostrara que: $\left(1 .^{\circ}\right)$ los médicos son incapaces de asegurar la competencia, voluntariedad y no ambivalencia de los pacientes cuando toman la decisión; $\left(2 .^{\circ}\right)$ los médicos no pueden comprender o aplicar el requerimiento de consentimiento informado para el tratamiento médico; $\left(3 .^{\circ}\right) \mathrm{o}$ si se probara que en otros países hay abuso de los pacientes, falta de cuidados o una pendiente resbaladiza respecto de la terminación de la vida. La Corte canadiense consideró, sin embargo, que una regulación permisiva con las debidas garantías era capaz de proteger a los enfermos vulnerables del abuso y del error. Los médicos podrían asegurar la competencia y plena libertad de los enfermos para decidir y podrían aplicar el estándar del consentimiento informado a este tipo de pacientes, como lo vienen haciendo sin problemas para los casos de limitación de esfuerzo terapéutico o de medicina paliativa con efecto colateral letal. Tampoco había pruebas concluyentes de que en los ordenamientos permisivos hubiera riesgos más altos de abuso o de error (p. 109). En conclusión, la Sentencia falla que la prohibición absoluta de la ayuda al suicidio no es la medida limitativa del derecho menos gravosa y, por consiguiente, es desproporcionada.

La Corte canadiense halla en la penumbra de la libertad constitucional un nuevo derecho fundamental, el derecho a ser ayudado a morir en determinadas situaciones, mientras que la Corte italiana no lo hace, sino que, a lo sumo (que tampoco es poco), amplía la limitación de esfuerzo terapéutico permitiendo el suicidio asistido, de modo alternativo a la sedación terminal (ya permitida), como forma de anticipar en el tiempo el desenlace fatal de una persona que no puede vivir sino gracias a la tecnología médica. En otras palabras, el suicidio asistido por médico se permite actualmente en Italia (por decisión judicial y aún no legislativa) como una modalidad alternativa de los enfermos terminales que dependan de un dispositivo de soporte vital (temporal o permanentemente), a fin de adelantar su fallecimiento, si de esta forma se garantiza mejor su convicción sobre la manera más digna de morir. Evidentemente, según la jurisprudencia italiana, la señora Gloria Taylor no hubiera tenido derecho a ser ayudada a morir puesto que no dependía de ningún mecanismo de soporte vital.

Así pues, aunque la Corte italiana cita en estrados a la Sentencia Carter en su ayuda, el tribunal canadiense falla, en realidad, en un sentido diametralmente opuesto al italiano. Según la Corte canadiense, no sirve la excepción de la prohibición de ayuda al suicidio al caso de la señora Taylor (u otros semejantes, a 
diferencia de lo decidido por la Corte italiana), sino que, con carácter general, «el Parlamento debe tener la oportunidad de dictar un remedio apropiado» (p. 125). En otras palabras, el Parlamento canadiense y los provinciales, en el ámbito de sus respectivas competencias, deberán dictar una nueva regulación que esté conforme con la doctrina vertida en la Sentencia. Esta doctrina identifica como inválida una prohibición penal de ayuda médica a morir para un adulto competente que $\left(1 .^{\circ}\right)$ consienta claramente la terminación de su vida; $\left(2 .^{\circ}\right)$ que tenga una determinada condición médica: enfermedad o discapacidad que le cause sufrimientos permanentes, intolerables e irremediables. El Tribunal suspende la declaración de invalidez de la norma penal impugnada durante un plazo de doce meses.

Esa reforma del Código Penal ${ }^{15}$ permitiendo la ayuda médica a morir (M.A.I.D. por sus siglas en inglés ${ }^{16}$ ) se aprobó en junio de $2016^{17}$. Actualmente en Canadá se permite el M.A.I.D., que comprende tanto el suicidio asistido como la eutanasia activa directa, para adultos capaces que sufran una «condición médica severa e irremediable», entendiendo por tal una enfermedad o discapacidad seria e incurable, hallarse en un avanzado estado de irreversible deterioro de la capacidad, con sufrimientos permanentes físicos o psicológicos que no puedan ser eliminados de modo aceptable y un horizonte de muerte natural «razonablemente previsible» teniendo en cuenta las circunstancias médicas. Se tienen que cumplir simultáneamente todas estas condiciones. McMorrow observa que el requisito más dudoso y discutible es el último, el de la muerte en un plazo «razonablemente previsible». A diferencia de las regulación del suicidio asistido por médico en los Estados en Norteamérica, a partir de la experiencia de Oregón, que permiten dicha forma de suicidio a los enfermos terminales, entendiendo por tales a los que tengan una esperanza de vida inferior a seis meses, en Canadá no se determina con exactitud el límite de la previsibilidad razonable de la vida ${ }^{18}$. En cualquier caso, las condiciones para acceder al M.A.I.D. son estrictas ${ }^{19}$. McMorrow pone como ejemplos de situaciones en las que no sería posible el de una persona con discapacidad por 40 años de dolor crónico de espalda o el de una víctima de un accidente de tráfico ocurrido hace 20 años y que le confina a andar con una silla de ruedas ${ }^{20}$.

15 Criminal Code RSC 1985, cC-46, s. 241

16 Medical assistance in dying.

17 Ver: Th. Mcmorrow: Voluntary Euthanasia, Assisted suicide E Law Reform: a Sketch of the Canadian Experience», en BioLaw Journal, Rivista di BioDiritto, 1/2019, pp. 268 ss.

18 Ibidem, p. 274. Se produce en torno a esta fórmula «una falta de claridad y consenso», p. 274.

19 Mcmorrow observa que por ello en Canadá hay quien discute su posible ampliación a otros supuestos no previstos actualmente: menores de 18 años, enfermos mentales, enfermos no terminales, etc. Quien defiende esta ampliación, sugiere que este tipo de enfermos se halla discriminado respecto de los que actualmente si pueden acceder al M.A.I.D, Ibídem, pp. 275 ss.

20 Ibidem, p. 274. 
La ayuda a morir en Canadá sigue siendo un delito muy grave, con una pena de hasta 14 años de reclusión, pero se exceptúa en el caso del M.A.I.D., que, como su propio nombre indica, es una ayuda «médica», esto es, proporcionada sólo por personal sanitario, en las condiciones estrictas indicadas. El procedimiento se abre con una petición que debe ser escrita, datada y firmada por un paciente mayor de 18 años plenamente capaz y libre para adoptar esta decisión; también debe ser firmada por dos testigos independientes. El personal sanitario debe asegurarse de que se cumplen todos los requisitos legales. Por supuesto, el paciente puede poner fin al procedimiento en cualquier momento. Inmediatamente antes de llevar a cabo la ayuda a morir, el personal sanitario debe dar la última oportunidad al paciente de abortar el proceso y se le vuelve a poner a la firma un documento de consentimiento informado. Son dos los médicos independientes que han de intervenir para garantizar que se cumplen todas y cada una de las condiciones legales. Desde que se firma el M.A.I.D. hasta que se lleve a cabo, deben transcurrir diez días, a fin de que el paciente pueda reflexionar sobre su decisión, aunque los dos médicos que intervienen podrían reducir este plazo si hay riesgo de pérdida inminente de capacidad o de muerte del paciente.

Así pues, las diferencias entre las decisiones de las Cortes canadiense e italiana son palmarias. La sentencia Carter en Canadá identificó un nuevo derecho, el derecho a recibir ayuda médica a morir en un contexto eutanásico, mientras que la sentencia Capatto tan sólo amplía el supuesto en que se puede prestar tal ayuda en una situación de limitación de esfuerzo terapéutico, como una alternativa válida a la sedación terminal, sin que de ningún modo se pueda entender que reconoce ningún derecho nuevo en este sentido.

\section{Una jurisprudencia aplicable del Tribunal Europeo de Derechos Humanos no tan inocua como señalan las decisiones italianas}

La Ordinanza (CD 7) menciona expresamente cuatro sentencias del Tribunal europeo de derechos humanos con relevancia como parámetro exegético de este caso: Pretty v. Reino Unido, de 20 de abril de 2002; Haas v. Suiza, de 20 de enero de 2011; Koch v. Alemania, de 19 de julio de 2012 y Gross v. Suiza, de 14 de mayo de 2013. La Sentencia (CD 2.2) sólo recuerda la famosa doctrina del caso Pretty según la cual de la Convención de Roma no se deriva ningún derecho a renunciar a la propia vida, esto es, a la propia muerte.

En efecto, la señora Pretty era una mujer de 43 años con una enfermedad neuro-degenerativa de las células motoras dentro del sistema nervioso central que, en el momento de presentar la demanda, estaba paralizada de cuello para abajo, no podía casi hablar y su esperanza de vida no era superior al año (de hecho, poco después falleció de forma natural), aunque conservaba intacta su capacidad intelectual. No existía ningún tratamiento médico que pudiera frenar la progresión fatal de la enfermedad. En Reino Unido, como en la mayoría de países, el 
auxilio al suicidio está tipificado penalmente. Pues bien, la Sra. Pretty se dirigió al responsable de la acusación pública inglesa, el Director of Public Prosecutions solicitando que no abriera diligencias contra su esposo si éste le ayudara a suicidarse según su propio deseo. La solicitud fue desestimada y el asunto se trasladó a los tribunales, donde finalmente la House of Lords confirmó la negativa porque aquel órgano no puede negarse a perseguir un delito. El Tribunal británico dijo no ser «un cuerpo legislativo, ni un árbitro ético». De modo que el asunto se trasladó a Estrasburgo. Los argumentos principales en relación con el art. 2 del Convenio de la demandante fueron dos:

1. Ayudarla a suicidarse no lesionaría el art. 2, pues de otro modo los países europeos donde el suicidio asistido no es ilegal estarían violando tal disposición. A esto contesta el Tribunal que no le correspondía en ese momento determinar si la legislación de otros Estados desconoce o no la obligación de proteger el derecho a la vida.

2. El argumento principal de la demandante fue que el art. 2 protege el derecho a la vida y también el derecho a elegir si se sigue o no viviendo. Protegería el derecho a la vida y no la vida misma, y lo haría frente al Estado y otros particulares, pero no contra uno mismo. Esta idea es rebatida radicalmente por el Tribunal. Después de reiterar la doctrina conocida sobre la «preeminencia» del art. 2, sin cuyo ejercicio «ninguno de los demás derechos y libertades de la Convención serían posibles», y la obligación que se deriva para el Estado de proteger la vida adoptando medidas adecuadas para salvaguardar la vida de aquellos que se hallen bajo su jurisdicción, el Tribunal resume el énfasis de su jurisprudencia sobre el art. 2 en «la obligación del Estado de proteger la vida». Pues bien, sostiene que «el Tribunal no está persuadido de que el derecho a la vida garantizado por el art. 2 pueda ser interpretado como que contiene una dimensión negativa». A diferencia de las libertades, como la de asociación del art. 11, que comprende la libertad de asociarse o de no hacerlo, «que implican alguna medida de elección sobre cómo se ejercitan», el art. 2 «es enunciado en diferentes términos». No se refiere, afirma el Tribunal, «a lo que una persona elige hacer con su vida». Esto, en su caso, debería reconocerse en otros preceptos del Convenio o en otros textos jurídicos. «Pero el art. 2 no puede, sin una distorsión del lenguaje, ser interpretado como si otorgara el derecho diametralmente opuesto, el derecho a morir; ni puede crear un derecho de autodeterminación en el sentido de conferir a un individuo la facultad de elegir morir más que vivir».

Esta doctrina no ha sido revocada por el Tribunal de Estrasburgo, pero sí fuertemente matizada en las sentencias que cita la Ordinanza (sentencias que, por cierto, de modo significativo, no son recordadas por la Sentenza). La Ordinanza sí 
menciona que, según el Tribunal europeo de derechos humanos, el derecho de cualquier persona a decidir cómo y en qué momento poner fin a la propia vida, siempre que se trate de personas capaces y de decisiones libres, es una de las facultades del derecho a «la vida privada» del art. 8 del Convenio de Roma. Pero rápidamente señala que este derecho puede ser limitable siempre que se respete el estándar de proporcionalidad (satisfecho plenamente, a su juicio, en el objetivo de proteger a las personas más vulnerables); y recuerda cómo, no existiendo un consenso entre los diversos Estados sobre este asunto, gozan de un amplio margen de apreciación. De modo que la prohibición italiana de ayuda a morir no vulneraría el art. 8 del Convenio de Roma.

La argumentación de la Corte Constitucional italiana en este punto es superficial, a mi juicio. En la medida en que las decisiones de la Corte amparan al señor Capatto y no llegarán, por tanto, a Estrasburgo, no sabremos qué habría fallado el Tribunal europeo sobre el sistema italiano de prohibición casi total de ayuda al suicidio.

$\mathrm{Y}$ esto es interesante porque la vigente jurisprudencia del Tribunal europeo sobre ayuda al suicidio, relativa casi siempre al permisivo sistema suizo (país donde, por cierto, acabaron sus días tanto el señor Antonioni como la señora Taylor), no es tan inocua o deferente (vía margen estatal de apreciación) respecto de los sistemas nacionales sobre ayuda a morir como interpreta la Corte italiana. Basta ver los tres casos de referencia posteriores a Pretty. El primero es Haas v. Suiza, de 20 de enero de 2011. El señor Ernst G. Haas, nacido en 1953, sufrió un serio trastorno bipolar durante 20 años. En ese periodo se intentó suicidar dos veces y recibió ayuda psiquiátrica. Solicitó una dosis letal de pentobarbital sódico (15 gramos) a varios médicos, sin éxito. Tampoco las autoridades administrativas y judiciales suizas se lo permitieron. El Tribunal europeo examina si el concepto de derecho a la vida privada del art. 8 del Convenio europeo de derechos humanos o Convenio de Roma (en adelante, CR) incluye el derecho a la ayuda al suicidio, concluyendo que es una facultad de ese derecho del art. $8 \mathrm{CR}$ el derecho personal a decidir por qué medio y en qué momento poner fin a la propia vida, siempre que el individuo sea capaz y totalmente libre de actuar en consecuencia. Esta doctrina la repetirá en todas las sentencias posteriores. Ciertamente, como veremos, el Tribunal europeo no amparará la pretensión concreta del señor Haas y recordará la falta de consenso nacional y, por tanto, el amplio margen de apreciación estatal para disciplinar esta materia, pero lo cierto es que el Tribunal halla en la penumbra del amplio derecho a la vida privada del art. $8 \mathrm{CR}$ un nuevo derecho a adoptar decisiones sobre el final de la propia vida, aunque sea bajo las condiciones estrictas que establezca cada ordenamiento nacional.

Aunque el Tribunal europeo afirme que «simpatiza con el deseo del demandante de suicidarse de una manera segura, digna y sin dolor» (p. 56), no va a amparar la petición del señor Haas porque éste no estaba en una situación de enfermedad terminal ni en un estado, a diferencia de la señora Pretty, que le impidiera suicidarse por su cuenta. La regulación suiza que le impide la 
obtención de la substancia letal, limitando de ese modo, su derecho, persigue un fin legítimo de protección frente a la adopción apresurada de decisiones y para prevenir abusos, asegurando, en particular, que un paciente sin capacidad pueda llegar a obtener una dosis letal de pentobarbital. Esto, según el Tribunal, es aún más necesario en un país como Suiza, donde la legislación y la práctica permiten de una manera relativamente fácil el acceso al suicidio asistido. La introducción de límites evita que las organizaciones de ayuda al suicidio actúen ilegalmente y en secreto, con riesgo de abuso (p. 57). Por tanto, la restricción en el acceso a dicha substancia es razonable para proteger la salud y seguridad públicas y para prevenir la comisión de delitos.

El Tribunal europeo no concede el amparo al señor Haas y sigue invocando la doctrina del margen estatal de apreciación, es cierto, pero también lo es que acuña un nuevo derecho en relación con las decisiones de una persona sobre el final de su vida y que, en consecuencia, son de interpretación estricta las medidas que, como la restricción de acceso a una substancia letal en este contexto, lo limiten. Las decisiones de la Corte Constitucional italiana en examen no adoptan este enfoque.

La doctrina del Tribunal europeo se reitera, como se ha indicado, en las dos sentencias posteriores que la siguen sobre este asunto, Koch v. Alemania, de 19 de julio de 2012, y, sobre todo, Gross v. suiza, de 14 de mayo de 2013 (Sentencia de Sala). En Koch la discusión es fundamentalmente procedimental porque se trataba de un caso en el que la mujer del demandante, tetrapléjica, solicitó sin éxito una dosis letal de droga al Instituto alemán federal de productos médicos y farmacéuticos; más tarde, acude a Suiza donde pone fin a su vida con la ayuda de una organización; y, al regresar a Alemania, su marido intenta conseguir una sentencia declarando la ilegalidad de la negativa del Instituto Federal. Sus demandas fueron rigurosamente inadmitidas en todos los niveles de la jurisdicción alemana y acude a Estrasburgo sosteniendo que ello lesionaba su derecho al respeto a la vida privada (art. 8 CR). Dada la estrecha ayuda que el demandante había prestado a su mujer, el Tribunal europeo falló que él también había sido directamente afectado por la negativa del Instituto a conceder a su mujer la dosis de pentobarbital sódico. De manera que estima que se ha producido una violación del art. $8 \mathrm{CR}$ en su dimensión procedimental.

Más interesante resulta, a nuestros efectos, el caso Gross. La demandante, nacida en 1931, había expresado durante muchos años su deseo de morir, por su avanzada edad y creciente fragilidad. Contactó con la organización Exit, de ayuda al suicidio, pero, dado que no estaba gravemente enferma, no le pudo asistir. Las autoridades suizas, tanto las administrativas como las judiciales, también rechazaron su petición. Finalmente, se suicidó (antes de recaer la sentencia de Gran Sala, y por ello ésta fue de inadmisión, el 30 de septiembre de 2014). Pero la Sala había ya dictado una sentencia muy interesante en 2013. La señora A. Gross llevó, pues, a las autoridades de su país ante el Tribunal europeo por negarse a proporcionarle una dosis de 15 gramos de pentobarbital 
sódico. Un caso semejante, pues, al de su compatriota el señor Haas. El Tribunal de Estrasburgo reitera la doctrina Haas, afinando la argumentación: «Sin negar el principio de santidad de la vida protegida bajo la Convención, este Tribunal ha considerado que, en una era de creciente sofisticación médica combinada con expectativas de vida más largas, mucha gente está preocupada por no verse forzada a vivir su vejez y el avance de su pérdida de condiciones físicas y mentales de un modo que entre en conflicto con sus ideas y convicciones sobre su autonomía e identidad» (p. 58). Así pues, el Tribunal identifica el riesgo de abuso de la tecnología médica, sobre todo en el marco de una sociedad europea crecientemente envejecida, como el poder cuyo desbordamiento hace necesario el reconocimiento del nuevo derecho de autodeterminación en relación con las decisiones del final de la vida. Concretamente, el Tribunal expresamente afirma que «el deseo de la señora Gross de que se le proporcione una dosis letal de la substancia que le permita poner fin a su vida cae dentro de su derecho al respeto a la vida privada bajo el art. $8 \mathrm{CR}$ ( (p. 60).

Desde ahí, recuerda la sentencia cómo en Haas el Tribunal consideró que era apropiado examinar la petición del demandante de la substancia letal sin receta médica a partir de la obligación positiva del Estado de adoptar medidas necesarias para permitir un suicidio digno. En el caso Gross, sin embargo, la cuestión es si el Estado suizo ha incumplido su deber de proporcionar suficientes orientaciones bajo qué circunstancias las personas pueden obtener una substancia de este tipo. El Tribunal concluye que sí ha incumplido tal deber y, en consecuencia, estima violación del art. $8 \mathrm{CR}$. Obsérvese que el Tribunal no llega a reconocer el derecho de la señora Gross a obtener el pentobarbital sódico, sino que se limita a estipular que Suiza no regula de modo adecuado las condiciones para su obtención. Ciertamente, a partir de las guías de ética médica, la práctica en Suiza es dispensar la receta de la substancia letal sólo cuando al paciente le quedan pocas semanas e incluso días de vida. La señora Gross no entraba en este supuesto porque no tenía una enfermedad terminal; ni siquiera estaba gravemente enferma, tan sólo estaba cansada de vivir.

Me parece evidente la línea que marca el Tribunal europeo de incluir el derecho al suicidio asistido en contexto eutanásico dentro del art. $8 \mathrm{CR}$. Porque me convence más el voto particular discrepante de la sentencia Gross, firmado por los magistrados Raimondi, Jocieve y Karakas, que observan que el ordenamiento suizo sí regula con precisión (en su legislación sobre prescripción de fármacos) las circunstancias bajo las cuales un médico está autorizado a recetar una dosis de una substancia letal y la señora Gross claramente estaba excluida por no tener una enfermedad grave y/o terminal. Y, sin embargo, el Tribunal llega a otorgar este amparo tan extraño, forzando un poco las cosas y avisando de su orientación futura. Obsérvese que los casos Haas y Gross se refieren a personas que no son enfermos terminales e incluso que, sobre todo en lo relativo a la señora Gross, ni siquiera están gravemente enfermos. Y el Tribunal no introduce esta capital distinción. Hasta ahora no ha enfrentado un supuesto claro que le permita establecer 
con mayor rotundidad los perfiles de este nuevo derecho que está en proceso de construcción, pero, cuando ocurra, es predecible el sentido en el que lo resolverá.

En cualquier caso, incluso en esta fase en la que el Tribunal de Estrasburgo aún no proporciona una doctrina lo suficientemente contundente como para cuestionar la regulación nacional de la ayuda al suicidio, se deduce la existencia de un nuevo derecho que, sin embargo, no es aludido por las decisiones italianas. La Corte Constitucional italiana pasa de puntillas sobre la jurisprudencia europea, lo que no hizo, por cierto, el tribunal milanés proponente de la cuestión.

\section{Análisis de fondo de las decisiones de la Corte Constitucional}

Evidentemente, la novedosa técnica decisional que ha empleado la Corte Constitucional, merece un análisis atento por su importancia. Afecta al balance de relaciones entre la jurisdicción constitucional y el legislador; a los límites en la creación de derechos por parte del juez constitucional; a los problemas que plantea este modo de decidir diferido en el tiempo. Hemos podido comprobarlo con este caso, en el que el legislador ha sido incapaz de alcanzar el consenso necesario para aprobar una ley en una materia tan delicada. No analizaré este asunto, sin embargo, por razones temáticas y de brevedad. En cualquier caso, tan sólo haré constar que a pesar de la larga lista de autores que, correctamente, a mi juicio, indican que el mejor modo de reconocer este nuevo derecho a decidir el modo y momento de la propia muerte en caso de enfermedad terminal debiera ser una ley y no una sentencia, lo cierto es que es un hecho obstinado que los tribunales constitucionales crean nuevos derechos fundamentales, normalmente a partir del «hallazgo» de nuevas dimensiones o facetas de derechos ya existentes.

Así que los derechos fundamentales nacen por Constitución o ley (parto natural), pero también, y más a menudo, por decisiones judiciales (por cesárea). De hecho, la mejor solución sería que este «nuevo derecho» encontrara, en primer lugar, acomodo en una reforma de la Constitución; más tarde en una ley especial (orgánica en el caso español) que desarrollara lo dispuesto por la Constitución y sólo más tarde en las decisiones judiciales que aplicarían estos preceptos y que podrían llegar a tener cierto valor creativo, pero sólo completando y sistematizando la regulación normativa. Pero la tozuda realidad es que, sobre todo en los temas éticamente sensibles y socialmente divisivos (que son, paradójicamente, aquellos donde la primacía del Parlamento a la hora de adoptar las soluciones debiera ser mayor), la incapacidad para alcanzar un cierto grado de consenso parlamentario se suele superar vía decisión judicial. Este es el hecho que debemos enfrentar.

Las decisiones italianas en cuanto al fondo del asunto, a diferencia de la canadiense y las europeas, no reconocen el derecho a la ayuda médica al suicidio, en contexto eutanásico, de ninguna manera. Al exigir específicamente, algo que ningún otro ordenamiento reclama, que el paciente dependa de algún tipo de 
mecanismo o tratamiento de soporte vital, como un respirador automático, ya sea de modo permanente o, como en el caso concreto, de modo temporal, el suicidio asistido por médico no es reconocido generalmente en Italia en los contextos eutanásicos, sino como una excepción estricta planteada como alternativa a la sedación terminal para evitar una prolongación indebida de la vida. Y siempre en supuestos de limitación de esfuerzo terapéutico (por la exigencia de la dependencia del tratamiento de soporte vital). F.A. tenía ya el derecho de que se le interrumpiera el tratamiento de soporte vital. También gozaba, como todo paciente, del derecho a la sedación terminal. Lo que ocurre es que ello no le aseguraba una muerte rápida, ni conforme a su idea de la propia muerte. Transcurrirían unos días hasta su deceso. Esta modalidad de fallecimiento es la que F.A. no consideraba digna; de ahí que la Corte Constitucional admita que en estos casos, pero sólo en estos casos (que no serán muchos), se puede proceder a un suicidio asistido a fin de adelantar la muerte. Y lo dice una vez que F.A. ya se había suicidado y es eficaz tan sólo respecto de la exoneración futura de la responsabilidad penal de quien le había ayudado transportándole hasta la clínica suiza, M.C. La decisión de la Corte llega con retraso respecto de una eventual habilitación del suicidio asistido de F.A. en suelo italiano. Por cierto, la Corte Constitucional no presta atención a un hecho que, sin embargo, es primordial, cual es que el suicidio tuvo lugar en Suiza de un modo válido según la lex loci (y no en Italia, donde estaba penalmente prohibida ${ }^{21}$ ); un hecho decisivo a la hora de determinar (más bien, de aminorar o exonerar) la responsabilidad penal de M.C.

De ahí que yo no comparta del todo la tesis fundamental de la Sentencia 242/2019. Según esta decisión, en los casos como el de F.A., es válido el suicidio asistido por médico, pero en el resto, no. Pues bien, resulta que, en el caso de F.A., el suicidio asistido no me parece una solución tan acuciante, puesto que podía haberse retirado su tratamiento de soporte vital e inducido una sedación terminal (tenía ese derecho), con el resultado muerte, mientras que en el resto de casos de enfermos terminales, con graves padecimientos, que lo desean y lo pidan, pero que no dependan de un tratamiento de soporte vital (y, por tanto, que no van a poder morir necesariamente de forma rápida, indolora y segura), se necesita, a mi juicio, reconocer ese derecho mucho más que en el de F.A.

Tripodina ${ }^{22}$ argumenta que la Constitución italiana (derecho de autodeterminación terapéutica: art. $32 \mathrm{CI}$ ) sí comprende actualmente el derecho «a dejarse morir», esto es, a no curarse, a rechazar un tratamiento, incluso de soporte vital. Una cosa es «dejarse morir» (limitación de esfuerzo terapéutico o eutanasia pasiva) y otra muy distinta «darse la muerte» (suicidio), hacerse ayudar a morir (ayuda al suicidio) o hacerse morir por mano ajena (eutanasia activa directa).

21 D. Pulitanò: "A prima lettura. L'aiuto al suicidio dall'ordinanza n. 207/2018 alla sentenza $n$. 242/2019», en Giurisprudenza Penale Web, 2019, n. ${ }^{\circ} 12$, p. 4.

22 C. Tripodina: «Quale morte per gli «immersi in una notte senza fine»? Sulla legitimità costituzionale dell'aiuto al suicidio e sul "diritto a moriré per mano de altri», en BioLaw Journal, n. ${ }^{\circ} 3,2018$, pp. 8 s. 
Estos otros supuestos derechos no están en la Constitución. Se pueden deducir vía interpretativa de derechos ya existentes, por supuesto, pero la conclusión será «fumosa», abundante en humo. De iure condito no se puede ayudar a morir a nadie. Otra cosa es de iure condendo. Hay una cesura que separa, de hecho, lo que es un derecho fundamental de lo que sigue siendo un delito. Por eso, en su opinión, el reconocimiento de este nuevo derecho requiere «un proceso de maduración colectiva» y luego «una decisión democrática». Se trata de romper uno de los tabús civilizatorios fundamentales: el de no matar.

La argumentación de Tripodina es sólida, pero no me resulta del todo convincente. Por supuesto que, como antes se indicó, lo deseable sería una reforma constitucional y legal en este sentido, precedida de un intenso diálogo social y político. Pero, en paralelo a este proceso democrático, existen, en mi opinión, suficientes argumentos jurídico-constitucionales como para sostener ya con cierto rigor la validez de la ayuda prestada a la muerte (tanto por vía del suicidio asistido como por la eutanasia activa directa) de los enfermos terminales con graves padecimientos físicos, psíquicos o morales, conscientes y libres que así lo deseen. Es posible disipar el humo de la arbitrariedad ideológica. De momento, ya tuvimos oportunidad de examinar la jurisprudencia del Tribunal de Estrasburgo que está aún en construcción, pero que apunta en la dirección del reconocimiento del derecho de autodeterminación corporal. En este sentido, es fácil suponer que si los dos casos principales planteados, Haas y Gross, ambos contra Suiza, se hubieran referido a enfermos terminales y no a otros, el Tribunal europeo hubiera sido todavía más contundente.

En cada ordenamiento, la interpretación será parcialmente diferente porque hay que prestar atención al propio catálogo constitucional de derechos. En el español, por ejemplo, creo que del derecho a la integridad personal del art. 15 CE, leído a la luz del principio del libre desarrollo de la personalidad del art. 10.1 $\mathrm{CE}$, se deriva un derecho fundamental frente al dolor físico y el derecho a tomar decisiones sobre la salud y sobre el final de la propia vida. En las decisiones italianas examinadas, el derecho afectado es aún más concreto, es el derecho a elegir el tiempo y la forma de la propia muerte (cuando ésta es ya inevitable). Creo que el art. $15 \mathrm{CE}$ comprende todos estos derechos. Habrá que esperar a una reforma constitucional o a una legal, más probable, pero también el Tribunal Constitucional podría declararlo en cualquier momento si se enfrentara a un caso adecuado para ello, como hiciera la Corte canadiense en su día. A mi juicio, existe ya un derecho constitucional, por ahora implícito (tanto que no siquiera se reconoce porque ninguna norma o sentencia lo ha hecho) de los enfermos terminales y/o con graves padecimientos físicos y psíquicos (tipo fases avanzadas de enfermedades degenerativas, enfermedades con síntomas refractarios, etc. —esto tendría que acotarse legalmente), mayores de edad, plenamente conscientes y libres para adoptar esta decisión, de recibir ayuda sanitaria a morir, con cargo al sistema nacional de salud, bien sea por suicidio asistido, bien por la intervención de un tercero sanitario. 
La Corte Constitucional italiana identifica la protección del enfermo terminal, en cuanto sujeto vulnerable, como la razón primordial para prohibir en general la ayuda al suicidio (y la eutanasia activa directa). Evidentemente, el ordenamiento tiene que proteger a las personas vulnerables (enfermas terminales con graves padecimientos en este caso) frente a su propia decisión en un contexto tan difícil. Pero este argumento por sí solo no explica por qué hay que proteger contra sí mismas a dichas personas cuando éstas no son tan vulnerables. Por eso, me parece un argumento a tener en cuenta, pero insuficiente para evitar la crítica por una carencia de fundamentación de una norma de paternalismo jurídico. Ya hemos visto cómo la Corte canadiense, con mejor criterio, creo, considera que no todos los enfermos terminales son sujetos vulnerables en este sentido. En mi opinión, no hay razones convincentes que justifiquen el paternalismo jurídico observado en este punto mecánicamente por la Corte italiana.

Obviamente, esto no significa ignorar las posibilidades de abuso sobre este tipo de pacientes y el riesgo de la denominada pendiente resbaladiza (aquello que pudiera ser justo en un caso concreto se generaliza descuidadamente al por mayor desvirtuando la eventual justicia de la medida individual). Pero estamos hablando de enfermos terminales (otra cosa es que fuera deseable concretar la inminencia temporal de la muerte: me convence más el modelo norteamericano que el canadiense en este sentido), con graves padecimientos físicos, psíquicos o morales, refractarios a su tratamiento y con su capacidad intacta para decidir. El riesgo de que adopte una decisión contra su voluntad es nulo si se estableciera un procedimiento con garantías.

Las decisiones de la Corte Constitucional italiana (también la canadiense y las del Tribunal de Estrasburgo) simplifican, a mi juicio, las razones que justifican la prohibición con carácter general del suicidio asistido. Además de la protección de los sujetos vulnerables, hay otras. Por ejemplo, el Informe del Task Force on Life $\mathcal{E}$ the Law del Estado de Nueva York (1994) menciona también: (1. $\left.{ }^{\circ}\right)$ Enfermedad mental no diagnosticada o no correctamente tratada. (2. $\left.{ }^{\circ}\right)$ Síntomas físicos manejados inadecuadamente. (3..$\left.^{\circ}\right)$ Insuficiente atención al sufrimiento y temores de los pacientes en trance de morir. $\left(4 .^{\circ}\right)$ Vulnerabilidad de grupos socialmente marginados. (5..$\left.^{\circ}\right)$ Devaluación de la vida de los discapacitados. (6..$^{\circ}$ Sentido de obligación: la legalización del suicidio asistido podría enviar el mensaje de que el suicidio es una respuesta socialmente aceptable a las enfermedades terminales o incurables. Algunos pacientes podrían sentirse presionados a tomar esa opción, particularmente quienes se sienten como una carga para los suyos. $\left(7 .^{\circ}\right)$ Deferencia del paciente hacia las recomendaciones del médico. (8..$^{\circ}$ Incentivos económicos a limitar los cuidados paliativos. El suicidio asistido es bastante más barato que los cuidados paliativos y de apoyo en el fin de la vida. (9..$^{\circ}$ Arbitrariedad de los límites propuestos. Será difícil, si no imposible, contener la opción del suicidio asistido a los enfermos terminales competentes con sufrimiento incontrolable; previsiblemente se extenderá a enfermos que no son competentes o que no son terminales. $\left(10 .^{\circ}\right)$ Imposibilidad de desarrollar un control efectivo. La 
naturaleza privada e íntima de este tipo de decisiones impedirá cualquier esfuerzo por controlar los eventuales errores y abusos.

No es este lugar para discutir uno por uno estos argumentos, u otros que pudieran suscitarse, como, por ejemplo, los aspectos simbólicos de la despenalización ${ }^{23}$, el deber de preservar la vida de los ciudadanos, de prevenir los suicidios (¿alguien quiere una sociedad de suicidas?) o de mantener la integridad de la profesión médica. Sí parece, en cualquier caso, razonable considerar que hay sólidos intereses públicos que pueden justificar la prohibición, con carácter general, de la ayuda al suicidio.

Parece también razonable, por consiguiente, seguir manteniendo la distinción entre la ayuda a morir, prohibida penalmente en general, y la ayuda en el morir, que es ya un derecho fundamental. No se ignora, sin embargo, que no pocos autores niegan esta distinción, a la que consideran un tanto hipócrita. Por ejemplo, R. Dworkin, quien subraya, incluso, que la eutanasia pasiva puede ser más cruel y más destructora de la humanidad que la activa: (negando la validez de la eutanasia activa y admitiendo la pasiva) «el derecho produce el resultado aparentemente irracional de que la gente puede elegir morir lentamente, negándose a comer, rehusando los tratamientos que la mantienen con vida, o asfixiándose al desconectar los respiradores, pero no pueden elegir la muerte rápida e indolora que sus médicos podrían fácilmente proveer ${ }^{24} \gg$. Un observador imparcial no experto que mirase desde la sala de un hospital dos escenas: cómo se interrumpe el tratamiento de soporte vital a alguien o se le seda y cómo se proporciona un medicamento letal a otra persona, no hallaría, en efecto, diferencias apreciables: una intervención médica, con intención paliativa que por último produce la muerte del paciente. Incluso la denominada eutanasia pasiva o limitación de esfuerzo terapéutico requiere un hacer, aunque su sentido fundamental sea el de omitir un determinado tratamiento. Y suele ir acompañada de la administración de medidas de doble efecto (paliativo y de adelantamiento de la muerte: eutanasia activa indirecta). Pese a todas estas dificultades, me parece que la distinción fundamental entre la eutanasia activa directa y la ayuda al suicidio y todo lo demás, puede seguir haciéndose con carácter general. Y es, además, un dato de derecho positivo en la mayoría de los ordenamientos, al menos por ahora.

Sin embargo, me parece que el paciente terminal tiene un derecho constitucional no sólo a que se le ayude en el morir, sino a que se le ayude a morir en el sentido que desee. Estamos hablando de enfermos terminales, con graves

23 La prohibición la ayuda médica a morir refleja la gravedad con que el ordenamiento contempla la decisión de privarse de la vida o de privarla a otro y la renuencia a aceptar o promover tales decisiones. Si se despenalizaran, ello reflejaría un cambio de valoración hacia esas conductas. Se convertirían en una medida más del arsenal de tratamientos médicos, con el riesgo añadido que ello supone.

24 El dominio de la vida. Una discusión acerca del aborto, la eutanasia y la libertad individual, Ariel, Barcelona, 1994, p. 240. 
padecimientos y con capacidad y libertad. En este supuesto, creo que los límites entre la ayuda a morir y la ayuda en el morir se desmoronan. Por la existencia de un derecho fundamental a no sufrir dolor o graves padecimientos que pudieran ser evitados. Por la libertad de elección en los momentos finales de la propia vida sobre cuándo y cómo morir. Y porque los pacientes terminales que tienen la «trágica desgracia ${ }^{25}$ » de no depender de un tratamiento médico de soporte vital no sean discriminados, esto es, tratados de modo desigual sin justificación alguna, respecto de aquellos pacientes que sí pueden pedir y obtener la desconexión de la medicina de aparatos. Hasta Tripodina indica que el argumento de la igualdad es un riguroso argumento que el Tribunal de Milán proponente de la cuestión de inconstitucionalidad debería haber utilizado.

Nuestra postura no está lejos de la que han propuesto varios profesores italianos de universidad, el Grupo de trabajo en materia de ayuda médica a morir, en el documento titulado «Ayuda médica a morir y derecho: por la construcción de un debate público plural e informado ${ }^{26}{ }$. Su tesis, que comparto, es que los pacientes con una enfermedad grave e irreversible, que produzca sufrimientos físicos o psicológicos intolerables y con capacidad de adoptar decisiones informadas y libres, deben poder tener el derecho a ser auxiliados bajo supervisión médica con cargo al sistema nacional de salud en su muerte si así lo desean, de acuerdo con un procedimiento que asegure la plena libertad y voluntariedad de la decisión y evite el riesgo de abuso y la pendiente resbaladiza. Por supuesto, debe reconocerse al personal médico el derecho de conciencia a negarse a intervenir en este proceso. Por otra parte, los colegios profesionales sanitarios deberían modificar sus códigos deontológicos para reconocer este nuevo derecho de los enfermos terminales a decidir cuándo y de qué modo morir. Esta nueva regulación debería ser objeto de una ley específica. Reconocer este nuevo derecho asegura la libertad y la igualdad constitucionales de los pacientes terminales.

Ampliar este derecho a otro tipo de sujetos diferentes de los pacientes terminales es un debate diferente y debe hacerse, en todo caso, con mucho cuidado. La situación de los enfermos con graves enfermedades degenerativas en estadios avanzados, por ejemplo, así como las personas con graves discapacidades que generen serio sufrimiento físico, psíquico o moral, es bastante semejante a la de los enfermos terminales. Por no hablar de los enfermos que puedan estar en esta situación pero que ya hayan perdido la capacidad de decidir. Todos estos supuestos merecerían una discusión específica, que excede con mucho el objeto de este trabajo. Y siempre siendo conscientes de que nos movemos en un campo donde no hay soluciones óptimas; nos movemos entre respuestas jurídicas malas y

25 S. Rodotá, citado por Tripodina, ibídem, p. 10.

26 www.biodiritto.org, 11 de septiembre de 2019. 
peores sobre un asunto que en sí mismo es terrible: la muerte de una persona. Son los «derechos infelices»de los que habla Massimo Donini ${ }^{27}$.

\section{CONCLUSIÓN: UNA JURISPRUDENCIA DE MAYOR VALOR SIMBÓLICO QUE PRÁCTICO}

En definitiva, la jurisprudencia italiana no transforma tan radicalmente el estado anterior de la cuestión, es decir, la prohibición absoluta de ayuda al suicidio. Parece dirigirse más al trágico pero concreto caso de D.J. Fabo, que a introducir nuevas reglas más permisivas en el sistema. Que nadie crea que la prohibición de la eutanasia activa directa y del suicidio asistido por médico en Italia se ha quebrado; al revés, sigue robusta. A lo sumo, la Corte ha dado muestras, aunque sea de una manera retroactiva porque el señor Antoniani ya había fallecido antes, de una cierta piedad hacia él y hacia quienes le ayudaron, en un caso especial, tanto por su dramatismo, como por ser altamente público ya que el afectado era un personaje famoso en su país, pasando por el hecho de tratarse de un ejemplo claro de litigación estratégica promovida por quienes desean que el ordenamiento introduzca el nuevo derecho de la ayuda a morir, y no sólo en el morir.

Este asunto no se asemeja a la Sentencia Carter v. Canadá, esta sí, una decisión que imprime un giro copernicano en el ordenamiento canadiense. Por lo que se refiere a la calidad de la argumentación, las decisiones de la Corte no toman suficientemente en cuenta, en mi opinión, la doctrina del Tribunal europeo de derechos humanos, ni argumentan con mayor profundidad, a diferencia de la Corte canadiense. En efecto, sostener la validez de la prohibición penal de toda forma de ayuda al suicidio basándose únicamente en la protección de los sujetos vulnerables, como son los enfermos terminales, sin tener en cuenta la propia voluntad, consciente y perfectamente razonable, de tales sujetos y, por tanto, sin esforzarse en argumentar con mayor rigor las razones que justifican un paternalismo jurídico de este tipo, no parece suficiente.

Ahora bien, que la jurisprudencia italiana no se acerque a la canadiense no quiere decir que sea totalmente irrelevante hacia el futuro. Porque las decisiones de la Corte sí difuminan, aunque sea sólo para un supuesto muy concreto en el que se deben dar conjuntamente varias circunstancias, (por lo que no es previsible su mayor aplicación posterior), sí fragilizan, insisto, las nítidas fronteras jurídicas entre la (permitida) limitación de esfuerzo terapéutico y la eutanasia activa indirecta (con la poderosa medida de la sedación terminal), también perfectamente válida según el protocolo sanitario vigente, con la eutanasia activa directa (ayuda al suicidio en este caso, más que eutanasia) que se sigue prohibiendo con carácter general. La Corte italiana crea, pues, una zona de penumbra, de grises y claroscuros que pueden permitir

27 Rivista Italiana di Medicina Legale, n..$^{\circ}$ 2/2016, pp. 559-581.

UNED. Teoría y Realidad Constitucional, núm. 46, 2020, ISSN 1139-5583, pp. 457-483 
en el futuro ir ampliando el reconocimiento del derecho al suicidio asistido en otras circunstancias que así lo aconsejen, menos estrictas que las fijadas ahora (sobre todo, si se eliminara el requisito de la dependencia de un tratamiento de soporte vital ${ }^{28}$ ). La Corte es consciente de ello y por eso se cuida de establecer numerosas cautelas y límites en orden a la regulación legal posterior. Siempre hay un riesgo de pendiente resbaladiza normativa o judicial. En definitiva, el valor de esta jurisprudencia es más simbólico, puesto que se ha roto un dique ideológico y normativo (la ayuda médica al suicidio se va a permitir bajo las condiciones que se han establecido) que práctico (tales condiciones son tan estrictas que es difícil imaginar que se apliquen a muchos otros casos en el futuro).

\section{****}

TITLE: Assisted-suicide in Italy: a new right?

AвSTRACT: In Italy, assisted-suicide is probibited criminally. Ordinanza n. 207 (2018) and the Sentenza n. 242 (2019) of the Costituzionale Court have, however, come to allow an exception: suicide-assited may be provided to terminally ill patients with serious conditions, if they depend on life-support medical treatment and have the capacity and freedom to decide. This paper concludes that this jurisprudence will be more symbolic than practical.

Resumen: En Italia, se prohíbe penalmente la ayuda al suicidio. La Ordinanza n. 207 (2018) y la Sentenza n. 242 (2019) de la Corte Costituzionale han venido, sin embargo, a permitir una excepción: se podrá prestar ayuda al suicidio a los enfermos terminales con graves padecimientos, siempre que dependan de un tratamiento médico de soporte vital y que tengan capacidad y libertad para decidir. Este trabajo concluye que esta jurisprudencia va a tener una eficacia más simbólica que práctica.

KEY WORDS: right to die with dignity; terminally ill; assisted-suicide medically; euthanasia.

Palabras Clave: derecho a morir con dignidad; enfermos terminales; suicidio asistido por médico; eutanasia.

FECHA DE RECEPCIÓN: 24.01.2020

FECHA DE ACEPTACIÓN: 09.09.2020

28 Con la doctrina de las decisiones en examen en la mano, si el legislador italiano permitiera el suicidio asistido por médico en contexto eutanásico, pero sin exigir este requisito de la dependencia de un tratamiento de soporte vital, tal regulación casi con total seguridad sería declarada inconstitucional por la Corte Constitucional (salvo si, obviamente, cambiara de interpretación, lo cual no parece muy probable). 
